\title{
UNDERSTANDING AESTHETICS IN DESIGN EDUCATION
}

\author{
Anna EGAN \\ OsloMet, Norway
}

\begin{abstract}
One of the more pressing issues that the product design profession faces today is that of sustainability. Within design education this is mainly addressed with a focus on the three $\mathrm{r}^{\text {`s: }}$ : recycling, reuse and repair. In her book entitled Aesthetic Sustainability: Product Design and Sustainable Usage, Kristine $\mathrm{H}$. Harper argues that another way to create sustainable products is to obtain aesthetic durability that provides the user with an emotional connection or aesthetic nourishment [4]. Such an approach requires both broad and in-depth knowledge of aesthetic ideas, something on which contemporary product design education can focus in new ways. This paper explores the challenges of aesthetics in design education through a pilot study that aims to identify possible problem areas and further research opportunities by asking the following research question: What are the challenges with teaching aesthetics in a product design programme at bachelor level, and how do the applied teaching methods provide students with versatile tools that can facilitate innovation through design? This study uses a phenomenological approach with a focus on qualitative methods, consisting of in-depth interviews with two teachers as well as three students in order to also capture the students' points of view. This method was triangulated with a literature review and an analysis of a variety of descriptions of aesthetics in the learning outcomes attached to each subject in the bachelor programme included in this study. The goal of these methods was to capture a multitude of perspectives on how aesthetics is taught and to discuss how this can empower students to use aesthetics in creating innovative and sustainable design solutions.
\end{abstract}

Keywords: Design, aesthetics, education, innovation, sustainability

\section{INTRODUCTION}

In this paper, the challenges of aesthetics in design education are explored through a pilot study aimed at identifying possible problem areas and further research opportunities. The author is a master's student with a background in product design. Despite being interested in the role that aesthetics plays in the creation as well as the enjoyment of products, the complex nature of aesthetics has made it difficult to obtain a holistic understanding of the subject. In his article entitled 'Models of design: Envisioning a future design education' [2], Ken Friedman discusses the challenges which designers may face in the future, as well as which tools they will need in order to tackle these challenges. He argues that the increasing demand for designers to work in a more interdisciplinary way requires a more flexible approach on the part of the designer. He suggests that designers should be proficient in science and technology, design, art and hermeneutics in order to provide valuable solutions to complex problems. This article will focus on the art aspect within design, which will be referred to as aesthetics throughout this paper. Aesthetics is a complex field of study that extends beyond the borders of design and is a central topic in the fields of art and philosophy [3]. Part of the challenge of aesthetics within product design is related to how it is defined and understood. This leads to the research question for this pilot study: What are the challenges with teaching aesthetics in a product design programme at bachelor level, and how do the applied teaching methods provide students with versatile tools that can facilitate innovation through design?

Initial discussions with postgraduate students in product design indicated that some students may feel a lack of confidence in their aesthetic knowledge, and that the level of aesthetic understanding can vary within the student base. The design students who were interviewed in this study reported that they considered the use of aesthetics to be very important for creating innovative and sustainable products. This raises the question of whether or not the teaching of aesthetics is providing students with the tools they need to create innovative products or whether new approaches should be considered and explored. 
An example of how aesthetics can be applied to complex problems within the context of design can be found in Kristine H. Harper's Aesthetic Sustainability: Product Design and Sustainable Usage, in which she conducted extensive research into a wide variety of aesthetic theories and practices, including an aesthetic strategy model which can be used to create meaningful design solutions [4].

\section{METHODS}

This study uses a phenomenological approach [1] in order to create an in-depth understanding of how students and educators experience the teaching of aesthetics within design education. The empirical data collected consists of in-depth interviews with two teachers and three students to also capture the students' points of view. The in-depth interviews with the students include survey questions, where the students evaluate their learning outcomes with regard to aesthetics as well as their attitudes towards the subject. This interview method was chosen in order to better understand the relationship between the teacher's intention and the resulting learning outcomes for the students. The abovementioned method was triangulated with a literature review and an analysis of references to aesthetics in the learning outcomes attached to each subject in the entirety of a three-year bachelor programme. The analysis was conducted in order to determine what knowledge the students are meant to have at the end of each subject course and is then compared to the self-reported evaluations of the students who were interviewed. The goal of these methods is to capture a snapshot of a multitude of perspectives on the challenges of teaching aesthetics and to determine to what degree these methods empower students to use aesthetics in creating innovative design solutions. The literature review was conducted prior to the interviews in order to establish background information and an understanding of the context of aesthetics in education. The literature review consisted of Aesthetic Sustainability: Product Design and Sustainable Usage [4], Arts and cultural education in Norway 2010/2011: Report [5] and two articles that focus on aesthetic exploration through crafting within the context of design education $[6,7]$.

\section{RESEARCH}

\subsection{Analysis of learning outcome}

The analysis of references to aesthetics in the learning outcome, attached to each subject in the bachelor programme are categorised by reference type to show how much attention is given to aesthetics in each subject. The graph shows the number of references as well as the type of reference. The subject codes and names have been anonymised for ethical reasons to protect the interests of the institution and the participants in this study. However, the numbering of subjects is chronological and indicates the progression of the bachelor programme.

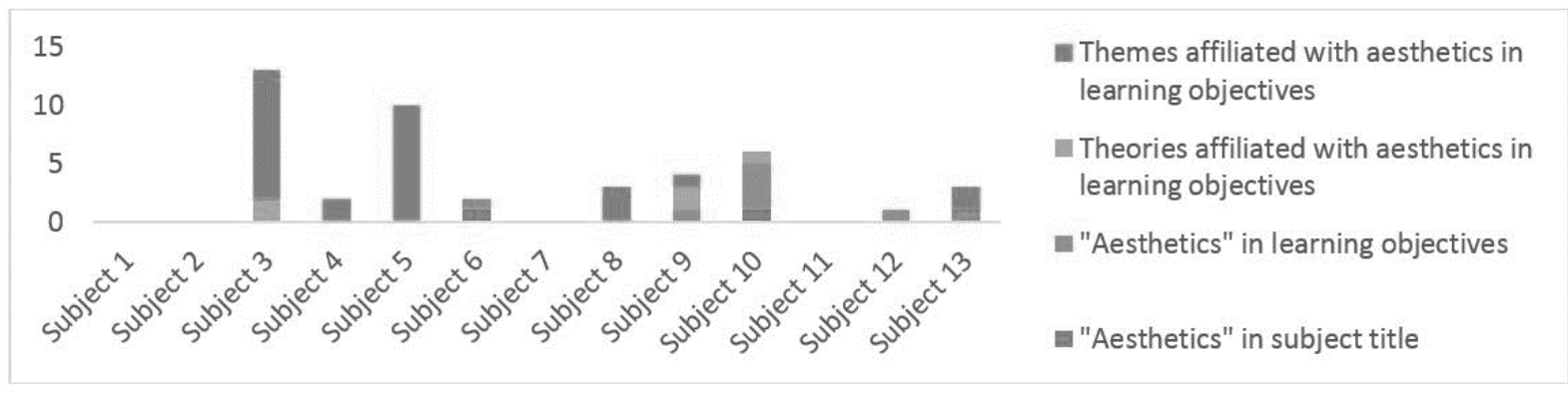

Figure 1. Visualisation of the analysis depicting aesthetic references in learning outcome

As can be seen from Figure 1, few explicit references are made to aesthetics in the learning outcome, although there is a lot of aesthetic content. This may result in subliminal learning, where students may unconsciously have retained aesthetic knowledge and practice, possibly with limited ability to articulate those insights. To examine this, the students were asked to rate their experiences of the teaching of aesthetics as mostly direct or indirect on a numerical scale. 


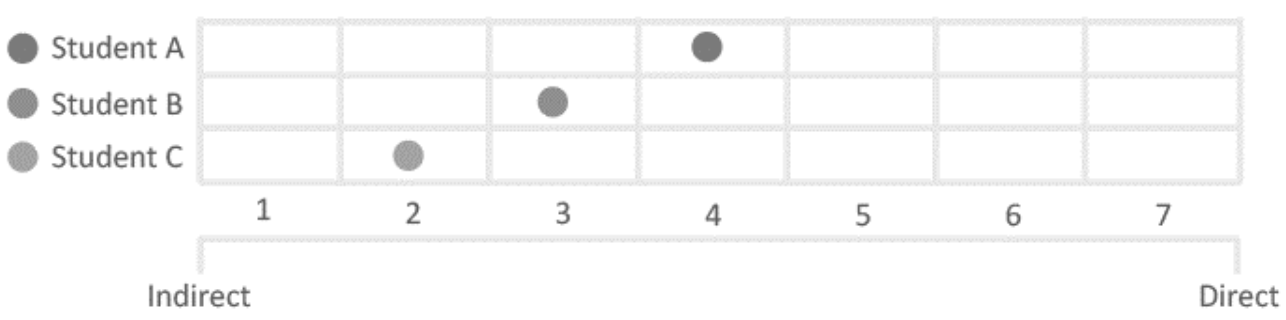

Figure 2. Visualisation of students' evaluation of aesthetic learning as direct or indirect

As Figure 2 illustrates, the three students who participated in this study reported that they experienced the overall approach to teaching aesthetics as more indirect, meaning that aesthetics was not mentioned specifically. Aesthetic principles, devices, methods and theories that touch upon the field were included in the teaching of subjects with another focus rather than directly, meaning that they were explicitly communicated through lectures, literature or delivery criteria.

\subsection{Student evaluation of aesthetics in learning outcomes}

Three students were interviewed during the course of this study. The students have been anonymised and will be referred to as 'Student A', 'Student B' and 'Student C' throughout this paper. Student A and Student B have completed the bachelor programme. Student $C$ has yet to complete the bachelor thesis but has reviewed the other subjects. The students that were selected represent a variety of perspectives within product design. Each interview lasted for approximately one hour. The interviews with Student A and Student B were conducted by video conferencing, while the interview with Student C was conducted in person.

Student A is currently undecided about their specialisation and has a more commercial view of aesthetics in design. The interview reveals that the main emphasis for aesthetics in their work is stylistic.

Student B is mostly focused on design of medical equipment, and their view on aesthetics is geared towards creating emotional relationships between the user and the product and on facilitating functionality.

Student $\mathrm{C}$ is more artistically inclined. As a ceramicist their work on aesthetics is experimental and explorative. This student has engaged actively in aesthetic design and has developed distinct expressions that challenge the concept of 'the beautiful'.

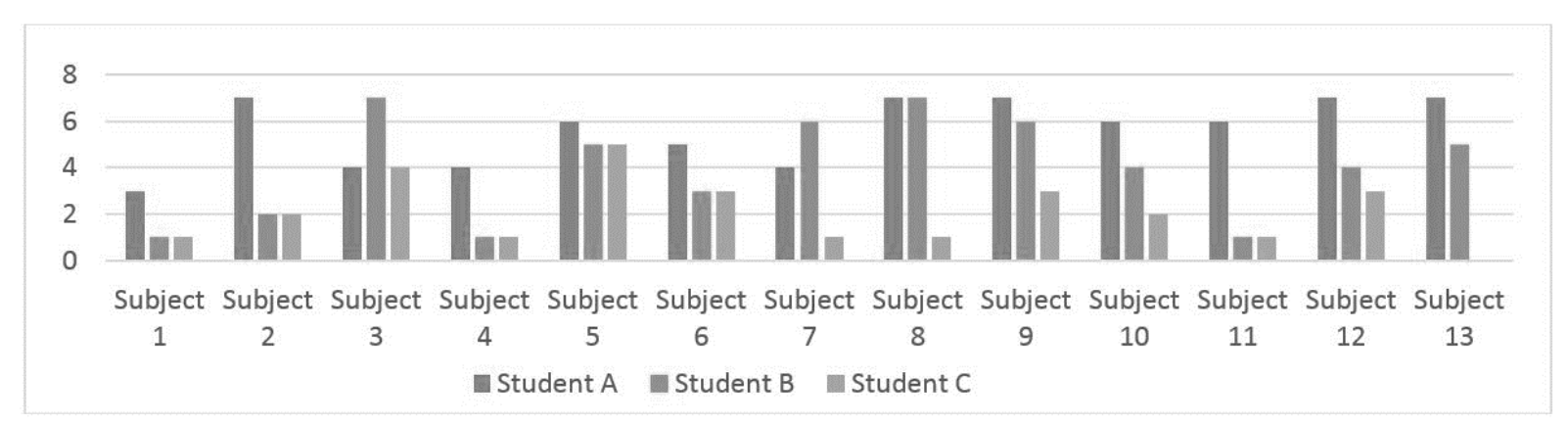

Figure 3. Visualisation of student evaluation of aesthetics in learning outcomes

Figure 3 visualises the self-reported evaluation of the aesthetic learning outcomes for each subject. The results in this graph were not correlated with the results in Figure 1 showing the number of aesthetic references. The graph in Figure 3 shows the students' evaluations when asked to rate their aesthetic learning outcomes on a numerical scale [1] ranging from 1 to 7 where 1 indicated the lowest learning outcome and 7 the highest. These results show that the students have very different experiences of each subject. A possible reason for this may be that the answers from each individual may be influenced by their level of confidence but may also be a consequence of how the subject was presented to them. These subjects are primarily project-based and offer students a high degree of freedom in pursuing different focus areas. Student A rates most of the subjects at the top end of the scale and defends these evaluations on the basis of enjoying the flexibility of project work and being able to explore aesthetics. 
Flexibility is important. In some of the subjects I have not given a 7 because I feel that it has not been enough. Or the course leader has not been interested enough to participate in a discussion about aesthetics, maybe because it does not interest them or maybe they don't have time. Still, I think that the structure of the subject enables you to explore questions about aesthetics.

Student A.

Student A valued the freedom of the project-based teaching programme, though felt that it lacked direction. The following quote from Student A indicates that although the subjects were rated at the high end of the scale, more theoretical input was desired.

I want a clear and distinct context in which aesthetics can be applied. Are there principles or tools that I can apply to only physical products? Digital products? What is the limitation? I really feel that the bachelor is put together so loosely. That when you finish the bachelor thesis, then presumably, you are really only at the beginning stage of your design education. I feel that my final outcome after the bachelor's degree is a little too open, a little too vague. Student A.

These thoughts were reflected in the following responses from Student C:

I think aesthetics shouldn't just be something that you learn on your own. Well, this is a bachelor degree that you have to research. I think something should be handed to you as well. I actually talked about this with my partner the other day and he's like, you don't really have enough tools in your toolbox as a designer. I'm good at figuring out problems, I can fix it and I can design anything from a chair to a lamp to a wheelchair, but the reason I say I can do anything is because I will research the problem and design from that. But I feel like I lack depth within me as a designer, what I should know for example about aesthetics. Student C.

Student B also made some reflections about the structure of the subjects and the desire for more specific theoretical input. Student B suggested that a reflection lecture might be implemented at the end of each subject, where teachers and students could engage in reflective discussions about the learning outcomes and experiences gained through the course module. Student B believed that the structure of the subjects did not need to be changed in a significant way, but that there was a need to find a method that could facilitate the conversion of unarticulated learning into conscious learning.

That's what I feel is a bit lacking in the programme. We don't get the baking mix, basically. We only get the ingredients without the recipe book. It's a bit like that, and sometimes it's okay to just get the ingredients and experiment, but feel free to give us the cookbook afterwards so we can find out what we did wrong, how we could have done it better. It's a bit like craftsmanship, you can never experiment with a method, such as clay or glazes if you don't know the basics. If you don't know how the composition of the clay works, then you might not understand how the chemistry behind a glaze works. As a result, you can't explore and experiment because you don't know the basics. Student B.

\subsection{In-depth interviews with the teachers}

During the course of this study, two teachers were interviewed in person, for approximately one hour and forty minutes each. The teachers have been anonymised and will be referred to as 'Teacher 1' and 'Teacher 2' throughout this paper. These teachers were chosen to provide broader insight into the subject, since Teacher 1 is focused on teaching practice-oriented approaches and Teacher 2 has more of an analytical approach.

Teacher 1 has a background in practice-led research and teaching in subjects related to aesthetics, culture, form and materiality.

Teacher 2 has a degree in design history and has extensive experience in analysing aesthetic elements in commercial products viewed in a historical and cultural context.

Both teachers expressed a strong interest in aesthetics, although they admitted substituting terminology with regard to aesthetics when communicating with students, as illustrated in this quote from Teacher 2 .

I don't think I often use the word aesthetics; I don't think I do. but I talk relatively often about quality. No. You probably use other terms such as balance or it exudes something specific,

instead of calling it something with aesthetics, you argue for what you have done. Teacher 2.

Teacher 1 also reflects on substituting the term aesthetics, both in the communicating with students and in writing research papers.

There has been a bit of resistance to the term aesthetics. But you know it's probably just that 
we've been weaned off using that word. There are a number of other areas, subject areas and concepts that have somehow taken over a bit and then it is overshadowed so that one might not talk about the tools. Because I think it's a part of it, that you don't have the tools grounded in you and it is not communicated well enough. Teacher 1.

This possible tendency to substitute aesthetics with another term may be detrimental for students who are endeavouring to learn about aesthetics. It may make it difficult for students to make the connection between aesthetics as a field and the theories and methods the students are learning about. However, substituting the term aesthetics is not necessarily limited to the institute involved in this study. Two articles that were included in the literature review, 'Values of crafting in design education' [6] and 'Ugly as a concept in craft to examine alternative futures' [7], both explore fascinating approaches to teaching aesthetics in design education. Interestingly, the term aesthetics does not appear in the heading or as a keyword in these articles. If the substitution of aesthetics as a term is an industry-wide phenomenon, it may make it difficult for students to locate and access literature and research on this subject unaided. The quote from Teacher 1 also resonates with an earlier statement from Student C in section 3.2 on student evaluation of aesthetics in learning outcomes. Both the teacher and the student recognise that the students may have a need for more in-depth learning of aesthetic tools.

\section{CONCLUSIONS}

The empirical data presented in this research paper is subject to a small selection of participants and is therefore to be considered a pilot project. Although the participants were carefully chosen to provide a broad spectrum of perspectives, there is not enough representative data to conclude anything definitive about design education in this institute or in general without further study. The aim of this research project was to explore what challenges are connected to teaching aesthetics in a product design programme at bachelor level. The data collected indicates that the students experience the overall approach to teaching aesthetics as indirect. Interviews with students reveal that they would welcome more aesthetic theory, but that a combination of theory alongside practice and reflective discussions would be preferable. The empirical data did not reveal a conclusive answer to the second part of the research question: how do the applied teaching methods provide the students with versatile tools that can facilitate innovation through design? However, the feedback from the students was collected and is presented in the following bullet points:

- Design direction. Student A expressed insecurities about how aesthetic tools, theories and methods can be applied within different branches of design. It could be interesting to conduct a study of students' views about implementing aesthetic elements differentiated between design specialisations that have different focus areas and purposes.

- Cultural analysis. The students gave positive feedback on the subjects that combined cultural understanding with aesthetics. This is an example of an approach that works well. Further research could be conducted in order to see whether the aesthetic strategy model described in Aesthetic Sustainability: Product Design and Sustainable Usage [4] would improve students' learning outcomes.

- $\quad$ Practical knowledge and theoretical knowledge. As mentioned above, the students included in this study believes that a combination of a stronger theoretical framework with practice and reflective discussions would be beneficial to students' learning outcomes.

- Linguistic definitions. Feedback from both teachers and students as well as findings from the literature review $[6,7]$ support the assumption that the term aesthetics is used infrequently. In addition to the concerns already raised in this paper, it is worth considering that design students often work collaboratively. Clear comunication is a key aspect of any collaberative design project, and it is therefore vital that terminology is used and understood in largely the same way by all participants.

As mentioned in the introduction, part of the challenge of aesthetics within product design is related to how it is defined and understood. Based on the feedback from the students regarding their learning outcomes, the preliminary conlusion for this pilot study is that the term aesthetics is largely undefined. This may partly explain why the students report having difficulties with holistically comprehending the nature of aesthetics, specifically how aesthetics can be used as a tool to further their work. These preliminary findings indicate that the design profession might benefit from re-establishing ownership of aesthetics as a term and as an asset by defining its characteristics and meaning for the field of design. In 
the pursuit of innovation as well as of creation of ethical and sustainable products, the field of design can scarcely afford to disregard such a potentsially useful tool as aesthetics.

\section{REFERENCES}

[1] Muratovski G. Research for designers: A guide to methods and practice. Los Angeles: Sage Publications; 2016.

[2] Ken F. Models of design: Envisioning a future design education. Visible Language. 2012;46(1/2):132.

[3] Nanay B. Aesthetics: A Very Short Introduction. Oxford: Oxford University Press; 2019.

[4] Harper K. H. Aesthetic Sustainability: Product Design and Sustainable Usage. 1st ed. Milton: Milton: Routledge; 2018.

[5] Bamford A. Arts and cultural education in Norway 2010/2011: Report. Bodø: Nasjonalt senter for kunst og kultur i opplæringen, 2012.

[6] Heimer A. M. Andreassen K. and Haugen S. Values of crafting in design education. 2017.

[7] Nuutinen A., Räisänen R. and Fernström P. Ugly as a concept in craft to examine alternative futures. European Journal of Futures Research. 2017;5(1):1-10. 